Erratum

Open Access

\title{
Erratum to \\ "Intranasal Delivery of Chitosan Nanoparticles for Migraine Therapy" [Sci Pharm. 2013; 81: 843-854]
}

\section{Neha GulatI ${ }^{*}{ }^{1}$, Upendra NAGAICH ${ }^{1}$, Shubhini A. SARAF ${ }^{2}$}

${ }^{1}$ Department of Pharmaceutics, School of Pharmacy, Bharat Institute of Technology, Meerut, UP, India.

${ }^{2}$ School of Biosciences and Biotechnology, Babasaheb Bhimrao Ambedkar University, Lucknow, India.

* Corresponding author. E-mail: ngulati88@gmail.com (N. Gulati)

Sci Pharm. 2013; 81: 1167-1169

doi:10.3797/scipharm.1208-18err

Published: $\quad$ October $6^{\text {th }} 2013$

Received: $\quad$ October $4^{\text {th }} 2013$

Accepted: $\quad$ October $6^{\text {th }} 2013$

This article is available from: http://dx.doi.org/10.3797/scipharm.1208-18err

(c) Gulati et al.; licensee Österreichische Apotheker-Verlagsgesellschaft m. b. H., Vienna, Austria.

This is an Open Access article distributed under the terms of the Creative Commons Attribution License (http://creativecommons.org/licenses/by/3.0/), which permits unrestricted use, distribution, and reproduction in any medium, provided the original work is properly cited.

\section{Abstract}

This is an erratum to the article 'Intranasal Delivery of Chitosan Nanoparticles for Migraine Therapy' [Sci Pharm. 2013; 81: 843-854]. Figures 1-3 are added.

\section{Keywords}

Erratum • Sci Pharm. 2013; 81: 843-854

Unfortunately, all three figures were missing in the published article [1]. The authors and the editorial office are very sorry for this error and for any inconvenience this caused. 


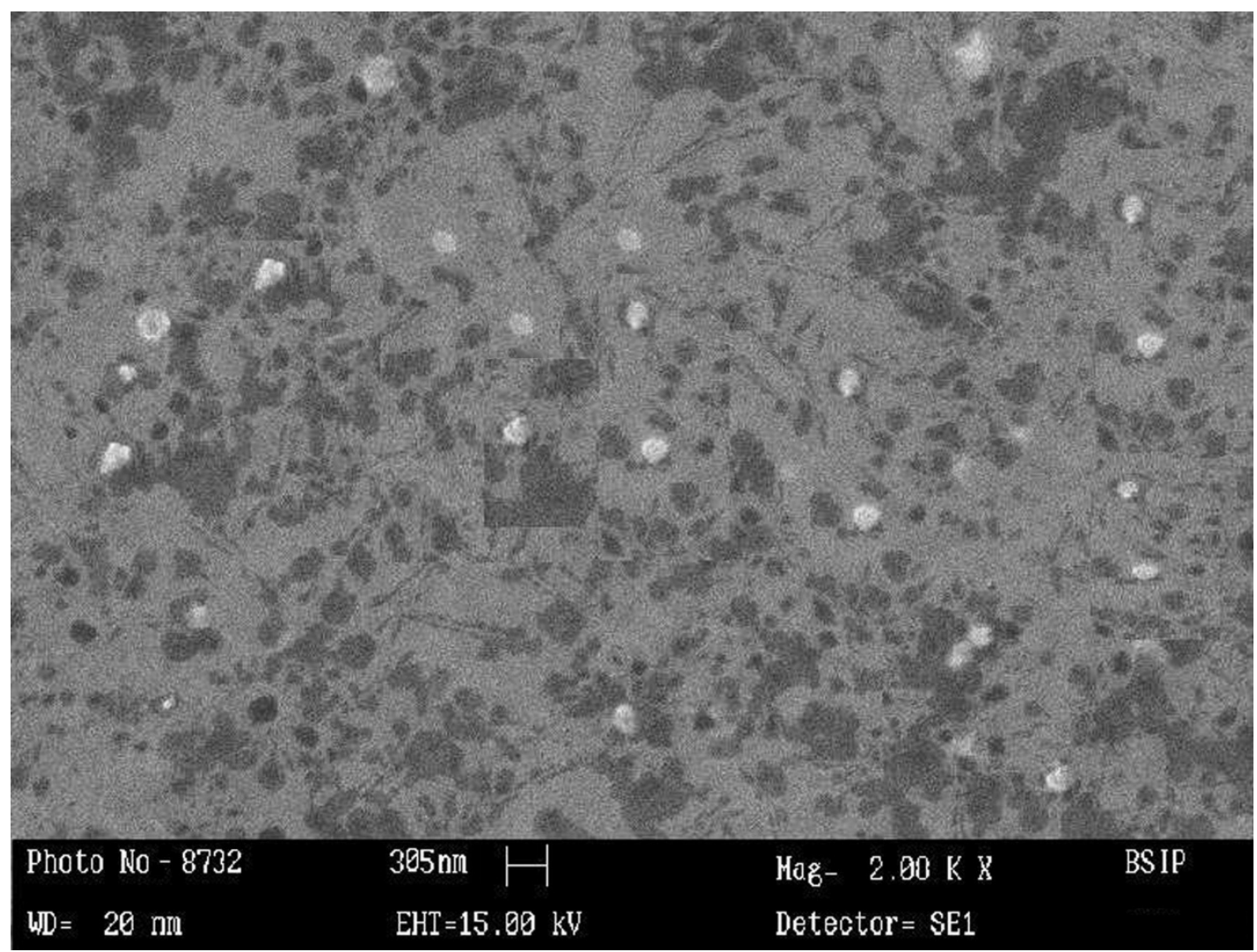

Fig. 1. SEM Photomicrograph of sumatriptan succinate loaded Chitosan nanoparticles

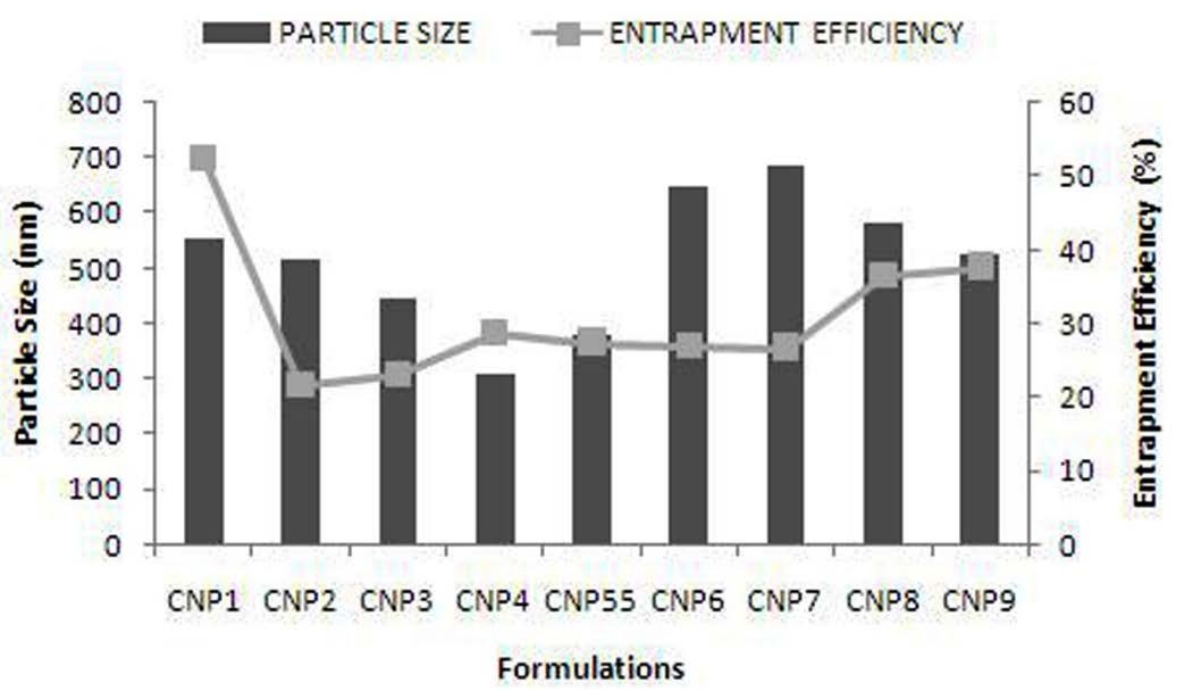

Fig. 2. Particle size and Entrapment Efficiency of nine formulations 


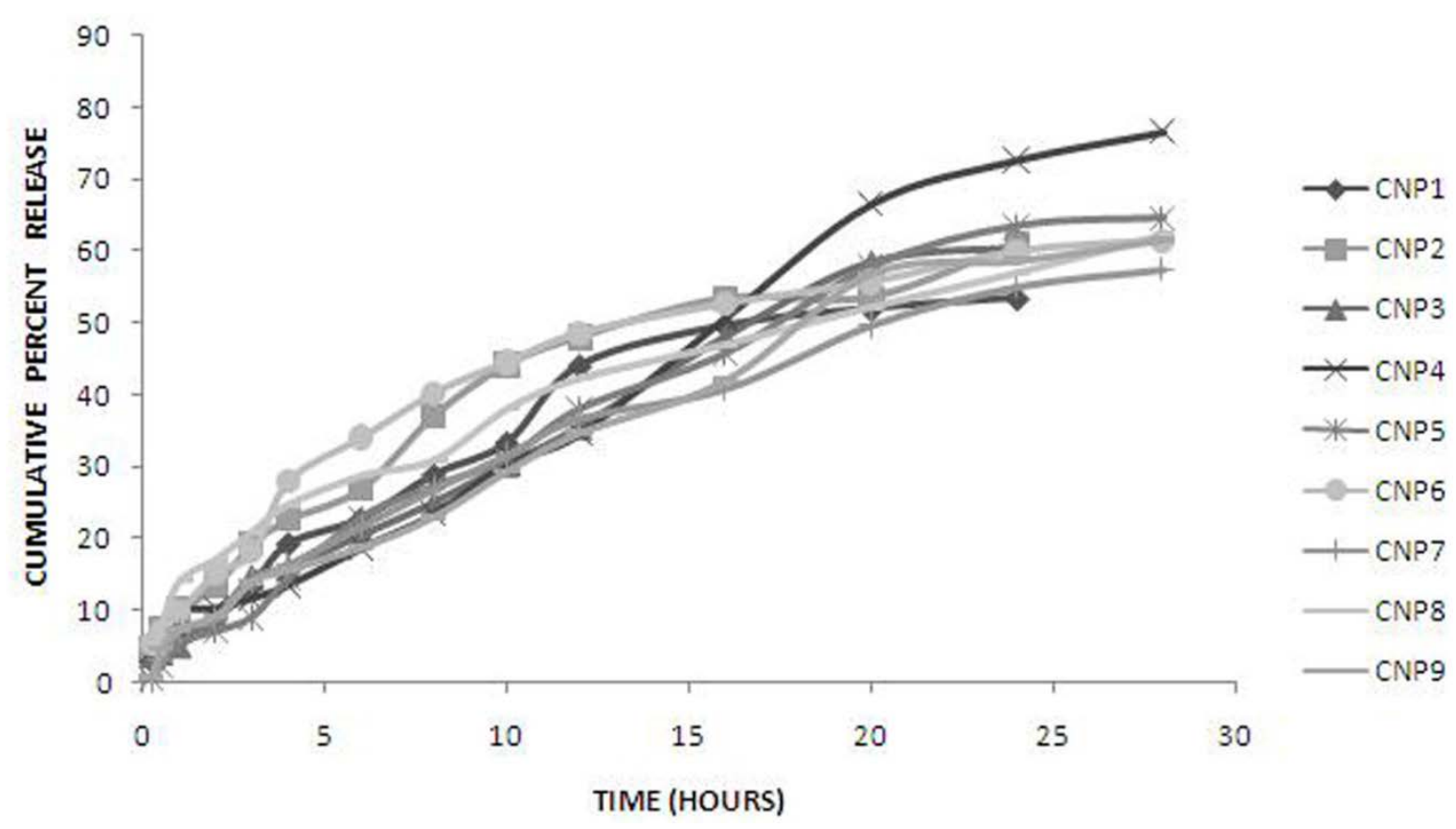

Fig. 3. In vitro drug release profiles of sumatriptan loaded chitosan nanoparticles

\section{Authors' Statement}

\section{Competing Interests}

The authors declare no conflict of interest.

\section{Reference}

[1] Gulati N, Nagaich U, Saraf SA.

Intranasal Delivery of Chitosan Nanoparticles for Migraine Therapy.

Sci Pharm. 2013; 81: 843-854.

http://dx.doi.org/10.3797/scipharm.1208-18 